\title{
THE DEVELOPMENT OF A FRAMEWORK FOR THE CLASSIFICATION OF TYPES OF B2B EC STRATEGIES
}

\author{
Jong-Min Choe* \\ Kyungpook National University
}

\begin{abstract}
Many prior studies have only investigated one or two kinds of business to business (B2B) electronic commerce (EC), and did not develop or suggest a framework for the classification of forms of B2B EC. This study focused on B2B EC with suppliers. Based on the degrees of information sharing between buyers and sellers as well as the levels of suppliers' power, we suggested a framework that is useful for classifying types of B2B EC strategies. According to this framework, four kinds of B2B EC strategies were proposed: electronic marketplace, electronic procurement, electronic partnerships and electronic distribution. With a cluster analysis, we empirically confirmed these four kinds of B2B EC strategies, and demonstrated the usefulness of a framework for the classification of types of B2B EC. The framework constructed in this study can be utilized in various ways. Specifically, when a firm wants to introduce B2B EC with suppliers, this framework can help a firm to decide and select an appropriate kind of B2B EC. This framework can also be applied to evaluate whether the proper form of B2B EC has been adopted or not.
\end{abstract}

Keywords: Electronic Commerce; Information Sharing; Suppliers’ Power; Resource-Based View; Transaction Cost Theory.

\section{INTRODUCTION}

In recent years, the implementation and use of business-to-business (B2B) electronic commerce (EC) in manufacturing firms to procure materials and parts from suppliers has become popular. Usually, the types of B2B EC that can be employed by manufacturing firms are grouped into four kinds: electronic marketplace, electronic procurement, electronic partnership and electronic distribution (Chang and Wong, 2010). However, the classification of these four types of B2B EC has never been based on a concrete and precise criterion or framework. Instead, the four kinds of EC seem to have been roughly taxonomized and proposed in prior studies. Hackney et. al. (2004) classified B2B EC into two types: electronic marketplace and electronic alliances. In some research, electronic partnership was not clearly differentiated from electronic

\footnotetext{
*Corresponding Author: Professor, Kyungpook National University, School of Business, Buk-ku, Sankyuk-dong 1370, Taegu 702-701, KOREA (South). Fax: 82-53-950-6247. Telephone: 82-53-950-5445, E-mail: choejj@knu.ac.kr
} 
marketplace, and they were considered as the same kind of EC (Son and Benbasat, 2007; Kurnia et. al., 2015). Some other studies did not precisely discriminate electronic procurement from the other types of EC, and the boundary between one type of B2B EC and another kind of EC was likely to be obscure in previous research (Dedrick et. al., 2008; Rai et. al., 2009).

It seems that since there has been no concrete framework, which supports the identification and validation of the types of B2B EC, the confusion in the classification of kinds of EC has occurred in prior studies. Previous research has not constructed or developed a framework for the classification of B2B EC, but has only suggested some kinds of EC. If a framework useful for the identification and taxonomization of kinds of EC is developed, a framework can be employed for manufacturing firms to identify and select an appropriate or required type of B2B EC under their circumstances. Researchers can also utilize the framework developed to decide, select and investigate the type of B2B EC, which is fitted with their research intentions or purposes.

Two broad categories of B2B EC include EC with suppliers and EC with customers. To develop a framework, this study focuses on EC with suppliers since information flows and cooperation through EC with suppliers are prerequisite conditions for value creation in manufacturing firms (Iyer et. al., 2009). To develop a framework, as classification criteria, this study employs the following two dimensions: degrees of information flow between focal firm and its main suppliers, and suppliers' power. The theoretical bases of adopting these two dimensions as classification criteria are the resource-based theory and transaction cost economics. The principal reasons why manufacturing firms implement B2B EC with suppliers include the fact that they actively want to obtain and utilize their suppliers' knowledge and capabilities, as it were, suppliers' resource through information sharing (Cheng and Fu, 2013; Youn et. al., 2014).

According to transaction cost economics, when firms trade with their partners, they try to choose the control mechanism of inter-organizational relationships, which most contributes to the minimization of transaction costs (Barua and Mani, 2014). However, the strength or weakness of suppliers' power affects the amount of transaction costs incurred in inter-firm relationships. Thus, according to the levels of suppliers' power, the relationships with suppliers are differently coordinated and controlled in order to minimize transaction costs (Dekker, 2004). In fact, the manufacturing firms' selection of a type of B2B EC, which works as one of the control devices in inter-firm relationships (Grover and Saeed, 2007), may depend on the degrees of usage of suppliers' resource through information sharing as well as the levels of suppliers' power, which must be controlled for achieving minimization of transaction costs.

In this study, based on both the degrees of information exchange between partners and the levels of suppliers' power, a framework for the classification of B2B EC was constructed and proposed. Through this framework, we suggest four kinds of B2B EC, 
which can be adopted by manufacturing firms. Finally, we empirically confirm the framework and demonstrate the four types of B2B EC.

\section{THEORETICAL UNDERPINNINGS}

\subsection{Resource-based View, Transaction Cost Theory, and Types of B2B EC}

According to the knowledge-based view, which is another facet of the resource-based theory, it is asserted that an organization can share and integrate necessary knowledge resources with its partners through collaborative information flows between an organization and partner firms (Wang et. al., 2013; Youn et. al., 2014). Inter-firm knowledge sharing or integration is defined as the extent to which a company exchanges and combines valuable insights and knowhow about its business-related context or matters with its trading partners (Cheng and $\mathrm{Fu}, 2013$ ). Inter-organizational knowledge sharing and integration can expand and supplement the supply of knowledge resources in an organization, and contribute to the acquisition of creative and distinctive knowledge, which leads to enhancement of organizational competitiveness.

From the knowledge-based perspective, it is represented that B2B EC has been shown to be a key means for the creation of shared knowledge in supply chains to respond to various types of uncertainties (e.g., product, technology and environment) (Son and Benbasat, 2007; Seddon, 2014). Inter-organizational information exchanges with B2B EC in buyer and supplier firms support the knowledge transfer, sharing and acquisition that are vital to intensifying their competitive positions (Cheng, 2011). Through B2B EC, inter-firm information flows are reinforced, and the strengthened information exchanges between involved firms give rise to knowledge transfer and sharing among related organizations. However, according to the types of B2B EC, there are considerable differences in the amount of information exchanged between buyer companies and suppliers (Wong et. al., 2012).

Transaction cost economics maintains that in inter-organizational relationships, firms choose the governance and control structures, which can minimize transaction costs and can raise the possibilities of attaining organizations' targeted performance (Barua and Mani, 2014). Transaction costs, also called coordination costs, include the costs of planning, adapting, executing and monitoring the completion of transaction tasks (Overby and Mitra, 2014). In inter-firm relationships, there are two forms of risk represented as relational risk and performance risk, which all directly link to increase of transaction costs (Das and Teng, 1996). Relational risk implies the probability and consequences of having a partner that behaves opportunistically. Performance risk indicates the risk of not achieving trading objectives, even when partners cooperate fully. When managers in a firm perceive high levels of both relational and performance risk, 
they adopt and apply appropriate governance arrangements and control mechanisms in a high degree to control these risks and reduce transaction costs.

Inter-organizational control devices are defined as a series of regulatory processes that control and coordinate transactional activities of buyer and supplier firms to overcome transaction risks and to achieve pursued goals of an organization (Dekker, 2004). Suppliers' strong power gives rise to high levels of transaction risks for buyers, especially, relational risk, and, as a result, the transaction costs charged to buyer firms are increased (Caker, 2008). If buyers are faced with high levels of trading risks caused by suppliers' power, they tend to pay more in searching partners, contracting with suppliers and monitoring transactions to successfully obtain their desired objectives. Thus, to reduce transaction costs, buyers' choice of inter-firm control structures rather depends on the strength of suppliers' power. Since through B2B EC, inter-organizational transaction activities can be controlled and coordinated, and the minimization of transaction costs can be attained, the types of B2B EC are regarded as complex forms of inter-firm control mechanisms (Grover and Saeed, 2007). From the transaction cost theory, which contends that firms decide and select types of inter-organizational control devices most contributing to minimization of trading costs, it is proposed that buyer firms' choice of kinds of B2B EC considerably depends on the strength or weakness of suppliers' power, which also affects transaction costs.

\subsection{Inter-organizational Information Exchange and Types of B2B EC}

Information exchange between trading firms has been considered as an effective mechanism to achieve high degrees of cooperation and knowledge sharing in inter-organizational relationships (Youn et. al., 2014). In B2B EC, for a focal firm to efficiently coordinate transaction tasks with its suppliers and to speedily respond to diverse classes of uncertainties, information of high quality, which refers to accuracy, usefulness and accessibility, has to be electronically shared between a buyer company and its partners (Hartono et. al., 2010). Market-based transactions are simply characterized as discrete contracts that represent relatively short-term and bargaining relationships between highly autonomous buyers and sellers (Ring and Van De Ven, 1992). In traditional market relationships, a minimum amount of information exchange between trading firms is sufficient since the buyer's goal is to fulfill an immediate need at the lowest possible cost. In an electronic marketplace, transaction information is mainly communicated between buyer firms and suppliers similar to a traditional market. An electronic marketplace almost shows the characteristics of a traditional market such as short-term relationships and a minimum amount of information sharing (Overby and Mitra, 2014).

In cases of electronic procurement and electronic partnerships, existing relationships with supplier firms can become more tightly coupled and continue for a longer period than in an electronic market. Thus, to maintain a close connection between a buyer firm 
and its partners, the amount of information exchanged in electronic procurement and partnerships is usually much more than what is exchanged in an electronic marketplace (Son and Benbasat, 2007; Chang and Wong, 2010). Frequent information flows in electronic procurement, with which the subsequent quick coordination of transaction activities, elimination of unnecessary trading processes, and efficient resources allocation or usage can be attained, contribute to the improvement of a buyer firm's supply-chain performance (Chang and Wong, 2010). To speedily respond to increased complexities of parts or products and expanded variations in demands or markets, a company has to communicate a large amount of highly qualified information with its suppliers (Youn et. al., 2014). However, the amount of information exchanged in an electronic marketplace is a little limited, and thus, a buyer firm seeking frequent and rich information sharing with its partners must choose kinds of B2B EC such as electronic partnerships.

Electronic partnerships are characterized by information flow integration and electronic integration in a supply chain (Patnayakuni et. al., 2006). An integrated information flow across the supply chain implies that a high degree of information symmetries and information sharing between trading companies can be obtained and sustained through inter-organizational information systems. The competitive benefits of coordination through information flow integration are expected to result in reduced operating costs, improved productivity and operational efficiency. Electronic integration is another facet or result of information flow integration. Electronic integration is the integration of the business processes of two or more independent firms through the exploitation of computer and communication technologies as well as the active utilization of the information being exchanged (Huo et. al., 2015). Electronic partnerships also provide opportunities for a focal firm to collaborate with its suppliers in such strategic business areas as new product development, joint $\mathrm{R} \& \mathrm{D}$ and cooperative cost management.

\subsection{Supplier's Power and Types of B2B EC}

Power means the capacity to exert one's will over others in order to realize certain intended benefits (Boonstra and Vries, 2008). When there exist a large number of contactable suppliers, which are almost same in satisfying the requirements of customers, and so, power of suppliers is very weak, customer firms can properly control the transactional relationships with suppliers through simply competitive bidding and not detailed contracts (Donada and Nogatchewsky, 2006). However, if power of suppliers is relatively strong, the transaction risks (i.e., the relational and performance risks) conceived by customer firms certainly increase. Since strong power of supplier firms is usually attributed from their specific capabilities (e.g., bargaining abilities and knowhow or skills) and their uniqueness or rarity, buyer's dependence on its supplier companies tends to be inevitably reinforced (Abbeele et. al., 2009). When the degrees of suppliers' power are high and customer firms highly depend on their powerful suppliers, customers must sustain intimate transactional relationships with supplier firms and may employ 
social controls, which are based on inter-firm trust, as a proper inter-organizational control mechanism (Donada and Nogatchewsky, 2006).

In an electronic marketplace, buyers and sellers have only a sales-to-purchasing interface, and buyer companies temporarily trade with many nonspecific suppliers for a short period of time (Huo et. al., 2015). Since the main characteristics of an electronic market include the fact that buyers' dependence on suppliers is very low and buyer firms can easily change their trading partners according to their intentions, the power of suppliers cannot be strong (Tang et. al., 2001). The general features of an electronic procurement show that in trading relationships with vendors, buyers take the initiative for executing transactions and buyers can select their proper vendors from numerous suppliers that contact the buyers' electronic procurement systems (Chang and Wong, 2010). In electronic procurement, only the vendor that is unilaterally chosen by buyer firms can provide parts or materials that exactly meet the requirements of buyers, and thus, the power of suppliers is relatively weak (Albrecht et. al., 2005).

Electronic partnerships indicate that buyer firms usually contact and trade with a small number of vendors that may have unique or rare capabilities, and so, their dependence on a few sellers in transactional relationships is absolutely high (Zhao and Xia, 2014). Although buyers' high dependence on suppliers gives rise to considerably strong power of suppliers, in electronic partnerships, close collaborative companions' relationships between buyer firms and a few sellers are formed and tried to be sustained for a long period. Through electronic partnerships, a buyer company can construct strategic partner relationships with its suppliers to exploit their complementary knowledge and capabilities in implementing cooperative projects such as joint new product development and R\&D (Zhu et. al., 2015). The formation of strategic electronic partnerships is not based on contracts but on information and common beliefs or trust. Buyer and supplier firms collaborating in electronic partnerships exchange strategic and confidential information and knowledge through inter-organizational information systems, and ultimately, these exchanges lead to inter-organizational learning.

\section{A FRAMEWORK FOR THE CLASSIFICATION OF TYPES OF B2B EC}

\subsection{A Framework Development}

The types of B2B EC can be identified, decided and selected based on the degrees of information exchange needed between manufacturing firms and their suppliers. Since B2B EC is a means to respond to various kinds of uncertainties and severe competitions through information or knowledge sharing (Youn et. al., 2014; Toit, 2015), the required or actual amount of information flows between buyers and sellers itself certainly reflects the adoption necessity of a specific kind of B2B EC. Supplier firms' power, which is attributed from their importance, uniqueness, and a buyer's dependence and asset 
specificity, positively affects the increase of transaction risks in a buyer firm (Abbeele et. al., 2009), which incurs a large amount of trading costs. In the views of transaction cost economics, since B2B EC is a complex inter-firm control device to lower transaction risks and reduce trading costs, according to the levels of supplier's power, different kinds of B2B EC must be adopted to control transactional relationship with a vendor firm. According to the degrees of inter-firm information flow or main suppliers' power, manufacturing firms may pursue different kinds of B2B EC. Thus, based on the levels of information exchange between a buyer firm and its main suppliers as well as the strength or weakness of main suppliers' power, a framework that also represents forms of B2B EC strategies adopted by manufacturing firms can be developed and proposed. Figure 1 shows the framework and the four types of B2B EC strategies: electronic procurement, electronic marketplace, electronic partnerships, and electronic distribution. In this study, the four types of B2B EC are recommended as EC strategies, since manufacturing firms strategically employ and utilize a specific kind of B2B EC under their circumstances.

Figure 1: A Framework for the Classification of Types of B2B EC

\begin{tabular}{|c|c|c|c|}
\hline \multirow{4}{*}{$\begin{array}{c}\text { Information } \\
\text { exchange }\end{array}$} & & \multicolumn{2}{|c|}{ Suppliers' power } \\
\hline & \multirow[b]{2}{*}{ High } & Low & High \\
\hline & & $\begin{array}{c}\text { Electronic procurement } \\
\text { strategy }\end{array}$ & $\begin{array}{c}\text { Electronic partnerships } \\
\text { strategy }\end{array}$ \\
\hline & Low & $\begin{array}{c}\text { Electronic marketplace } \\
\text { strategy }\end{array}$ & $\begin{array}{c}\text { Electronic distribution } \\
\text { strategy }\end{array}$ \\
\hline
\end{tabular}

\section{2. $\quad$ Electronic Marketplace}

When both the necessity to communicate information between buyer firms and their suppliers and the degrees of supplier's power are low, an appropriate kind of B2B EC for the buyer and vendor firms is an electronic marketplace. In an electronic marketplace, prices may act as the main coordinating devices by signaling all relevant information to buyers and sellers, and buyer firms can utilize simple contracts to regulate transactional relationships with many nonspecific suppliers (Dekker, 2004). In manufacturing firms that adopt an electronic marketplace strategy, the stage of their products in the product life cycle is apt to be more mature one. Accordingly, their manufacturing strategies are likely to be mass production oriented and focused on the production of standardized goods that need the communication of basic information about products.

\subsection{Electronic Procurement}

Manufacturing firms can employ an electronic procurement strategy in the cases that high degrees of information exchange between buyers and sellers, which is caused by high levels of uncertainties in markets or demands and technologies, are required as well 
as the degrees of suppliers' power are low. Through an electronic procurement strategy, buyer firms, which take the initiative, can select the best vendors from a large number of suppliers. The large amount of information that flows between buyer firms and their suppliers in electronic procurement contributes to the buyers' realization of the competitive benefits of $\mathrm{B} 2 \mathrm{~B}$ EC, such as quick coordination of transactional tasks, integration of transaction processes and acquisition of novel knowledge (Hartono et. al., 2010).

\subsection{Electronic Partnerships}

Manufacturing firms can adopt an electronic partnerships strategy when a large amount of inter-organizational information exchange, which is incurred by various kinds of uncertainty in the environments, is needed and the levels of suppliers' power are high. The manufacturing firms that employ type of electronic partnerships may produce highly customized products and greatly depend on a few vendors that provide specific parts or materials. Accordingly, buyer firms must closely collaborate with a few suppliers for the execution of their production. In this partnership, complex contracts are not sufficient for the regulation of inter-firm relationships with suppliers. Instead, in electronic partnerships, to sustain close collaborative relationships with a few vendors, trust-based social controls are a prerequisite.

\subsection{Electronic Distribution}

Electronic distribution is characterized by suppliers' very strong power as well as a very low necessity to share information between buyers and sellers. Buyer firms can choose an electronic distribution strategy when both the amount of information exchanged between buyers and their vendors is small, since they almost produce standardized products and the degrees of environmental uncertainties are very low, and supplier firms take the authority to sell and distribute parts or materials demanded by buyers. In electronic distribution, manufacturing firms can employ detailed contracts as control mechanisms to suppliers, and they can also supplement the controls for relationships with vendors through a small amount of information sharing. Actually, electronic distribution may be given to buyer firms, and they cannot construct and develop it by themselves and only can decide whether they participate in an electronic distribution EC or not.

\section{RESEARCH METHODS}

\subsection{Sample and Data Collection}

Data for this study were drawn from a survey of the current status of B2B EC used in Korean manufacturing firms. In total, 500 organizations were randomly selected from a 
population of about 1,000 firms that are listed on the Korean stock market. The manufacturing firms listed are medium to large in size and consequently, are likely to have more experience with B2B EC applications than smaller firms. First, the chief production managers or executives of the selected firms were contacted to ask for their participation in the research. At the beginning, 101 organizations responded to the request for information. However, during the survey, 9 firms withdrew from the survey, and as a result, 92 manufacturing firms were included in the research. In order to collect data, this study both administered questionnaires and conducted interviews with the participating firms. Only chief production managers or plant executives were selected as respondents. Before mailing the questionnaire, through an initial telephone interview with the respondent, the researcher of this study roughly asked him the firm's present conditions, such as adoption degrees of B2B EC. The results of the first interview generally concurred with the results of the questionnaire response. A questionnaire with a cover letter was mailed to each respondent. After distributing the questionnaire, through a second telephone interview, the contents of the questionnaire and the answering method were explained. The survey was conducted during a 3-month period between October 2013 and January 2014. To collect more empirical data, the survey was performed again on October 2015. In the second survey, from 60 manufacturing firms to which questionnaires were mailed, we obtained 13 firms' valid data. Accordingly, the final total sample size is 105 . Table 1 summarizes the sample characteristics according to the industrial type of the firms.

Table 1: Sample Characteristics

\begin{tabular}{|c|c|c|c|c|c|c|c|c|c|c|c|}
\hline $\begin{array}{c}\text { Type } \\
\text { of industry }\end{array}$ & 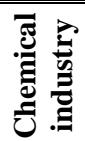 & 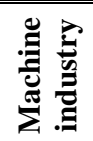 & 䒠兽 & 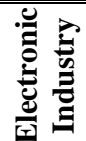 & & تृ & 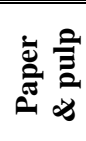 & 咅苞 & 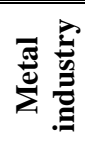 & $\frac{\grave{\Xi}}{\bar{z}}$ & है \\
\hline No. of firms & 22 & 17 & 19 & 14 & 5 & 3 & 3 & 8 & 11 & 3 & 105 \\
\hline $\begin{array}{c}\begin{array}{c}\text { No. of } \\
\text { employees }\end{array}\end{array}$ & $\begin{array}{l}8 \\
\frac{8}{3} \\
\frac{0}{0} \\
0\end{array}$ & $\begin{array}{l}\text { 8े } \\
\text { p. } \\
1 \\
0\end{array}$ & $\begin{array}{l}\text { Lे } \\
1 \\
\text { \&े }\end{array}$ & 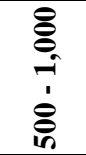 & छे & 荧 & & & & & \\
\hline No. of firms & 17 & 20 & 22 & 17 & 29 & 105 & & & & & \\
\hline
\end{tabular}

\subsection{Measurements}

Inter-organizational information exchange indicates the degrees of information sharing between a buyer firm and its main suppliers for the execution of its transactions. Based on the four items' measures developed by Cheng (2011), it was measured on a seven-point Likert-type scale that ranged from 'strongly agree' to 'strongly disagree'. The four items include frequent exchange, always sharing, exchanging all kinds of information, and sharing of proprietary information. 
The levels of suppliers' power were measured by the three items, which were developed and validated in the studies of Son et. al. (2005) and Cheng (2011). Respondents answered the extent to which they agree or disagree with each item. A seven-point Likert-type scale was used to measure the degrees of power. The three items are main suppliers' authorities (power) in decisions, transactions, and EC adoption.

The degrees of B2B EC adoption represent the usage degrees of the electronic marketplace, procurement, partnerships, and distribution for manufacturing firms to purchase parts or materials from their main suppliers. Based on the measures of Barua et. al. (2001) and Dedrick et. al. (2008), the usage degree in each kind of B2B EC was measured by the purchasing ratio of each type of B2B EC (i.e., purchasing volume of each kind of B2B EC for the year 2013 was divided by the total purchasing volume for the year 2013). Respondents provided the purchasing ratios for each types of B2B EC. The degrees of B2B EC adoption in manufacturing firms were calculated by the summation of the purchasing ratios of the electronic marketplace, procurement, partnerships, and distribution.

Supply-chain performance implies the degrees of improvement or reduction in transaction tasks and costs through B2B EC. The four question items, which were developed by Hartono et. al. (2010) and Youn et. al. (2014), were utilized to measure it. The levels of supply-chain performance were measured on a seven-point Likert-type scale, anchored by 'strongly disagree' and 'strongly agree'. The four items include costs and time reductions, and improvement of transaction tasks and response capabilities.

\section{DATA ANALYSES AND RESULTS}

\subsection{Reliability and Validity}

Item analyses were performed with Cronbach Alpha coefficients for all multi-item scale measurements. All Alpha coefficients were above 0.8, which is satisfactory for the reliability of a multi-item scale. Principal component analysis with a varimax rotation was used to verify the construct validities of the questionnaire items. Using a 0.4 criterion for significant item loading on a factor, the results show that all items within each index are represented by a single factor. The results of factor analysis are presented in Table 2.

Table 2: Results of Reliability and Validity Test

\begin{tabular}{lccccccc}
\hline \hline \multicolumn{1}{c}{ Items Factor } & $\mathbf{1}$ & $\mathbf{2}$ & $\mathbf{3}$ & $\mathbf{4}$ & $\begin{array}{c}\text { Eigen } \\
\text { value }\end{array}$ & $\begin{array}{c}\text { \% of } \\
\text { variance }\end{array}$ & $\begin{array}{c}\text { Alpha } \\
\text { coefficient }\end{array}$ \\
\hline Supply-chain performance & 0.91 & 0.95 & 0.95 & 0.89 & 3.5 & 35.1 & 0.96 \\
Information exchange & 0.73 & 0.81 & 0.87 & 0.79 & 2.6 & 26.0 & 0.82 \\
Suppliers' power & 0.92 & 0.93 & - & - & 1.8 & 18.4 & 0.87 \\
\hline \hline
\end{tabular}

Note: *Factor loadings below 0.4 were not presented. 


\subsection{Empirical Evidence of the Four Types of B2B EC Strategies}

With a cluster analysis, this study classified sample firms according to the levels of inter-organizational information sharing and suppliers' power. In the current study, cluster analysis provides groups of companies that are similar in terms of the degrees of inter-organizational information exchange and main vendors' power. In the cluster analysis, we used the hierarchical agglomerative method to form clusters because it generates non-overlapping clusters and it has been the dominant method. For the sorting or linkage rules, Ward's method was chosen since this technique optimizes minimum variance within clusters. We also used the squared Euclidean distance as the proximity measure.

Based on the values of information sharing between buyers and their main sellers as well as their main suppliers' power, a cluster analysis was performed to find four clusters of organizations: the electronic marketplace, procurement, partnerships and distribution strategies. In addition, the mean scores of information exchange and suppliers' power were calculated for each cluster. A critical issue in cluster analysis is to determine the optimal number of clusters. While there are formal decision rules to guide this process, heuristics are commonly used. A formal approach in determining the most appropriate number of clusters is to examine the distance coefficient. The distance coefficient is presented in table 3 . The points at which the distance coefficient suddenly jumps indicate suitable stages in the clustering sequence for analysis.

Table 3: Distance Coefficients of Cluster Analysis

\begin{tabular}{ccccccccccc}
\hline \hline Stage & $\mathbf{9 5}$ & $\mathbf{9 6}$ & $\mathbf{9 7}$ & $\mathbf{9 8}$ & $\mathbf{9 9}$ & $\mathbf{1 0 0}$ & $\mathbf{1 0 1}$ & $\mathbf{1 0 2}$ & $\mathbf{1 0 3}$ & $\mathbf{1 0 4}$ \\
\hline Coefficient & 32.4 & 37.8 & 44.1 & 52.9 & 62.0 & 77.3 & 109.3 & 149.0 & 202.3 & 306.3 \\
$\begin{array}{c}\text { Increasing rate } \\
\text { of coefficient }\end{array}$ & - & $16.6 \%$ & 16.6 & 19.9 & 17.2 & 24.6 & 41.3 & 36.3 & 35.7 & 51.4 \\
No. of cluster & 10 & 9 & 8 & 7 & 6 & 5 & 4 & 3 & 2 & 1 \\
\hline \hline
\end{tabular}

In Table 3, the distance coefficient increases greatly at two points - between the fifth and sixth clusters, and between the fourth and fifth clusters. This implies that the six-cluster and five-cluster solutions may be appropriate points for analysis. To show various cases in the combination of the degrees of inter-organizational information sharing and suppliers' power, the six-cluster solution can be selected. The six-cluster result provides suitable data to examine the variations in inter-organizational information exchange and main vendors' power. Therefore, the six-cluster solution is used in the analysis. The mean values of variables within each cluster are presented in table 4, along with the Kruskal-Wallis test results ( $\chi^{2}$ values) for each clustering variable. The $\chi^{2}$ scores indicate that statistical differences exist for the individual variables across clusters. 
Table 4: Results of Cluster Analysis (Kruskal-Wallis Test)

\begin{tabular}{|c|c|c|c|c|c|c|c|}
\hline Items & 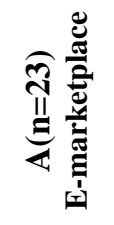 & 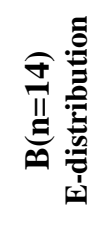 & 㣽 & 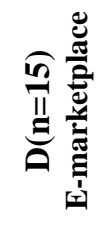 & 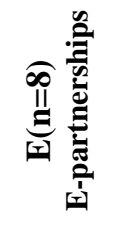 & 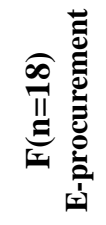 & $\chi^{2}$ \\
\hline IIE & $3.5(4)$ & $2.8(5)$ & 4.1(3) & $2.5(6)$ & $5.9(1)$ & $5.2(2)$ & $76.2^{\mathrm{a}}$ \\
\hline SP & $1.9(6)$ & $5.3(2)$ & $3.6(3)$ & $2.5(4)$ & $6.0(1)$ & $2.2(5)$ & $81.8^{\mathrm{a}}$ \\
\hline
\end{tabular}

Notes: The numbers are mean scores, and the numbers in parentheses are rankings. IIE: Inter-organizational information exchange, SP: suppliers’ power, a: $\mathrm{p}<0.01$.

Since in this study, a seven-point Likert-type scale was used for the measurements of inter-organizational information sharing and suppliers' power, the middle score (i.e., four-score) can be employed as the common dividing point with which the levels can be roughly classified into two groups: high and low. In the case of cluster E, the mean values of inter-organizational information exchange and sellers' power are higher than the middle point. Thus, cluster E may represent firms that prefer an electronic partnerships strategy. In the case of cluster B, the mean value of inter-organizational information sharing is lower, but that of suppliers' power is higher than the middle score. Accordingly, B shows the manufacturing firms adopting an electronic distribution strategy. However, in the cases of clusters $\mathrm{C}$ and $\mathrm{F}$, the mean values of information exchange between buyers and sellers are higher, but those of vendors' power are lower than the middle point. The firms of clusters $\mathrm{C}$ and $\mathrm{F}$ may prefer and pursue an electronic procurement strategy. In clusters $\mathrm{A}$ and $\mathrm{D}$, the mean values of inter-organizational information sharing and suppliers' power are considerably lower than the middle score. Thus, clusters A and D may indicate manufacturing firms adopting an electronic marketplace strategy.

In terms of inter-organizational information exchange and main sellers' power, the differences between $\mathrm{E}$ (electronic partnerships) and $\mathrm{C}$ (electronic procurement), and between $\mathrm{E}$ and $\mathrm{D}$ (electronic marketplace) were examined using the Mann-Whitney test and were found to be significant at the $5 \%$ or $1 \%$ level. Between B (electronic distribution) and $\mathrm{D}$ (electronic marketplace), no significant difference was shown in inter-organizational information sharing, but the score of suppliers' power in B was significantly higher than that of D. Comparing B with C (electronic procurement) shows that the degree of inter-organizational information exchange in $C$ was significantly higher than that of B, but in suppliers' power, that of B was significantly higher. In criterion variables between $\mathrm{E}$ (electronic partnerships) and $\mathrm{B}$, information sharing in $\mathrm{E}$ was significantly higher, and the level of sellers' power in E was slightly higher. The results from these comparisons between clusters are represented in Table 5. Figure 2 shows the location of each cluster on the grid of degrees of information exchange and suppliers' power. These results seem to support the assertion that types of B2B EC 
strategies adopted by manufacturing firms are generally grouped into the four kinds.

Table 5: Differences between Two Clusters (Mann-Whitney Test)

\begin{tabular}{|c|c|c|c|c|c|c|c|c|c|c|}
\hline $\begin{array}{l}\text { Cluster } \\
\text { Items }\end{array}$ & 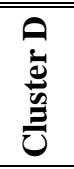 & 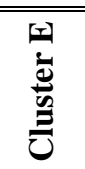 & $\begin{array}{l}U \\
\vdots \\
\vdots \\
0 \\
0 \\
0\end{array}$ & 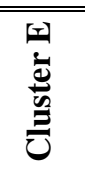 & 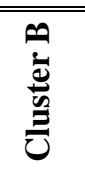 & 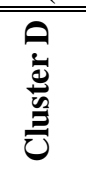 & 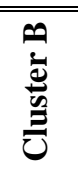 & $\begin{array}{l}u \\
\vdots \\
\vdots \\
0 \\
0 \\
0\end{array}$ & 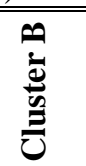 & 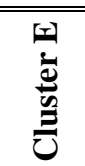 \\
\hline $\begin{array}{l}\text { Information } \\
\text { exchange }\end{array}$ & \multicolumn{2}{|c|}{$\mathrm{U}=0.0^{\mathrm{a}}$} & $\begin{array}{r}11.2 \\
\mathrm{U}\end{array}$ & $\begin{array}{l}18.5 \\
5.0^{\mathrm{b}}\end{array}$ & $\begin{array}{r}15.3 \\
\mathrm{U}=\end{array}$ & $\begin{array}{l}13.5 \\
.5\end{array}$ & $\begin{array}{l}9.7 \\
\mathrm{U}=\end{array}$ & $\begin{array}{l}24.9 \\
.0^{\mathrm{a}}\end{array}$ & $\begin{array}{l}7.0 \\
\mathrm{U}=\end{array}$ & $\begin{array}{l}18.0 \\
.0^{\mathrm{a}}\end{array}$ \\
\hline $\begin{array}{l}\text { Suppliers' } \\
\text { power }\end{array}$ & $\begin{array}{r}8.0 \\
\mathrm{U}\end{array}$ & $\begin{array}{l}18.3 \\
0^{\mathrm{a}}\end{array}$ & $\begin{array}{r}10.0 \\
\mathrm{U}=\end{array}$ & $\begin{array}{l}22.2 \\
0^{\text {a }}\end{array}$ & $\begin{array}{r}22.8 \\
\mathrm{U}=\end{array}$ & & $\begin{array}{r}34.7 \\
\mathrm{U}=\end{array}$ & $\begin{array}{l}15.0 \\
5^{\mathrm{a}}\end{array}$ & $\begin{array}{r}11.3 \\
\mathrm{U}=\end{array}$ & $\begin{array}{l}16.9 \\
5^{c}\end{array}$ \\
\hline
\end{tabular}

Notes: The numbers are mean ranks, a: $\mathrm{p}<0.01, \mathrm{~b}: \mathrm{p}<0.05$, c: $\mathrm{p}<0.1$. D: e-marketplace, B: e-distribu tion, C: e-procurement, E: e-partnerships.

Figure 2: Location of Each Cluster on the Grid (B2B EC Strategies)

\begin{tabular}{|c|c|c|c|c|c|}
\hline \multirow{6}{*}{$\begin{array}{l}\text { Information } \\
\text { exchange }\end{array}$} & \multicolumn{4}{|c|}{ Suppliers' power } & \multirow{6}{*}{4.0} \\
\hline & & $F$ & & $F$ & \\
\hline & & & C & & \\
\hline & $\mathbf{A}$ & & & & \\
\hline & & D & & B & \\
\hline & 1.0 & \multicolumn{3}{|c|}{4.0} & \\
\hline
\end{tabular}

\subsection{Characteristics of the Four Types of B2B EC Strategies}

In Table 6, the mean scores of organization size and age, adoption ratios (\%) in each types of B2B EC, total adoption ratio of B2B EC, and supply-chain performance in each cluster are presented, and can be compared across clusters. In this study, size is the number of employees of a firm in the year 2013 and the organizational age is measured by counting the years elapsed since the founding of a firm. In clusters $\mathrm{F}$ and $\mathrm{C}$ pursuing an electronic procurement strategy, the organization size is relatively larger than that of other clusters. This result seems to show that in Korean manufacturing firms, the largest companies usually have strong authorities to their suppliers, and thus, they may prefer the electronic procurement strategy. In cluster $\mathrm{F}$, the adoption ratios of both electronic procurement and B2B EC are the highest, and these highest ratios may reflect the sufficient resource capabilities of the largest firms, which represent the first ranking in supply-chain performance.

Cluster $\mathrm{C}$, which has the third ranking in organizational size and the second rankings in adoption ratios of an electronic procurement and B2B EC, shows the third order in supply-chain performance. In cluster E, which belongs to the group of an electronic 
Table 6: Differences of Characteristics among Clusters (Kruskal-Wallis Test)

\begin{tabular}{|c|c|c|c|c|c|c|c|}
\hline Items & $\begin{array}{c}\text { Cluster } \\
\text { A }\end{array}$ & $\begin{array}{c}\text { Cluster } \\
\text { B }\end{array}$ & $\begin{array}{c}\text { Cluster } \\
\text { C }\end{array}$ & $\begin{array}{c}\text { Cluster } \\
\text { D }\end{array}$ & $\begin{array}{c}\text { Cluster } \\
\text { E }\end{array}$ & $\begin{array}{c}\text { Cluster } \\
\text { F }\end{array}$ & $\chi^{2}$ \\
\hline Organizational size & $842.9(2)$ & $187.2(6)$ & $700.0(3)$ & $674.2(4)$ & $390.6(5)$ & $3,295.2(1)$ & $16.5^{\mathrm{a}}$ \\
\hline Organizational age & $38.9(1)$ & $36.6(3)$ & $32.6(5)$ & $37.5(2)$ & $29.6(6)$ & $34.3(4)$ & 1.35 \\
\hline $\begin{array}{l}\text { Adoption ratio of } \\
\text { e-marketplace (\%) }\end{array}$ & $8.6(3)$ & $4.5(6)$ & $7.0(4)$ & $9.2(2)$ & $4.8(5)$ & $10.3(1)$ & 2.67 \\
\hline $\begin{array}{l}\text { Adoption ratio of } \\
\text { e-distribution (\%) }\end{array}$ & $3.5(2)$ & 3.6(1) & $2.5(4)$ & $1.8(6)$ & $2.2(5)$ & $3.3(3)$ & 2.15 \\
\hline $\begin{array}{l}\text { Adoption ratio of } \\
\text { e-procurement (\%) }\end{array}$ & $12.0(3)$ & $8.1(6)$ & $21.8(2)$ & $8.4(5)$ & $11.0(4)$ & 22.3(1) & $10.8^{\mathrm{c}}$ \\
\hline $\begin{array}{l}\text { Adoption ratio of } \\
\text { e-partnerships (\%) }\end{array}$ & 20.8(5) & $34.5(2)$ & $22.5(4)$ & $13.7(6)$ & $33.0(3)$ & $38.8(1)$ & 5.98 \\
\hline Adoption ratio of $\mathrm{B} 2 \mathrm{~B} \mathrm{EC}$ & $43.5(5)$ & $50.8(4)$ & $53.8(2)$ & $33.1(6)$ & $51(3)$ & $64.5(1)$ & - \\
\hline Supply-chain performance & $3.6(4)$ & $3.4(6)$ & $3.8(3)$ & $3.6(4)$ & $4.0(2)$ & $4.9(1)$ & $12.1^{\mathrm{b}}$ \\
\hline
\end{tabular}

Notes: The numbers are mean scores, and the numbers in parentheses are rankings, a: $p<0.01, b: \mathrm{p}<0.05, \mathrm{c}: \mathrm{p}<$ 0.1. A \& D: e-marketplace, B: e-distribution, C \& F: e-procurement, E: e-partnerships.

partnership, the organization size and age are the smallest, and the actual adoption ratio of an electronic partnership is a little high. The ranking of cluster E in supply-chain performance is the second. Vendors may have stronger power over the buyers in cluster E, which is small in size, and as a result, buyer firms are likely to employ an electronic partnership strategy, which can bring close cooperation with suppliers through trust-based social controls as well as a large amount of inter-organizational information sharing. In cases of clusters A, B, and D, which are groups of electronic marketplace or distribution, actual adoption ratios are 2 - 9\%, and the usage ratios of B2B EC and the supply-chain performance are also relatively low or poor. From these results, it is assumed that a high adoption ratio of an appropriate kind of B2B EC and a high total usage ratio of B2B EC can contribute to the improvement of supply-chain performance.

\section{CONCLUSION AND DISCUSSION}

In this study, based on the degrees of information sharing between buyers and sellers, and the levels of suppliers' power, we suggested a framework that is useful for classifying types of B2B EC strategies in manufacturing firms. According to the framework, four kinds of strategies were proposed and empirically confirmed: the electronic marketplace, procurement, partnerships, and distribution strategies. In the case of the characteristics of each strategy, the size and the adoption ratio of B2B EC of the firms employing an electronic procurement were the largest and highest. In manufacturing firms belonging to the group of electronic procurement, when their actual adoption ratio of an electronic procurement strategy was highest, their supply-chain performance was also represented as the highest ranking. The result that the size of the companies adopting an electronic procurement is the largest shows the fact that Korean big firms have a superior position to their suppliers, and this large firms' feature (i.e., 
superior power) is generally consistent with the classification criterion of an electronic procurement. In this study, it was observed that the size of the firms employing an electronic partnership is small. This result seems to indicate that Korean small firms have a relatively weaker position to their suppliers, and accordingly, as a competitive strategy, they have to pursue close collaborations with their vendors to utilize their partners' knowledge and capabilities. The result of this study also showed that when the actual adoption ratio of an electronic partnership strategy in companies belonging to the group of electronic partnership is high, the ranking of their supply-chain performance is relatively high.

In manufacturing firms belonging to the group of electronic marketplace or distribution, the actual adoption ratios were not high, and rather, the adoption ratios of an electronic partnership in these companies were relatively high. The rankings of supply-chain performance in these firms were also not high. From these results, it is assumed that if the actual adoption ratio of an appropriate type of B2B EC is very low, this low adoption ratio may cause the decrease of supply-chain performance. In the case of organizational age, there were no meaningful differences. Many prior studies have investigated and proposed some kinds of B2B EC. However, they mostly focused on one or two types of B2B EC, and did not develop and suggest a framework for the classification of forms of B2B EC.

The framework, constructed in this research, can be utilized in various ways. When a firm wants to introduce B2B EC with suppliers, this framework helps a firm to decide and select an appropriate kind of B2B EC. The framework can also be applied to evaluate whether a proper form of B2B EC has been adopted or not. In addition, the framework can be employed and utilized in future studies. The discordance between the required type of B2B EC and the actually adopted form of B2B EC and the negative affect on supply-chain performance can be empirically examined in future research. With the framework, the kinds of B2B EC can be identified, and the influence factors for the adoption of each types of B2B EC may be investigated. In future research, a more advanced classification framework, which is useful for the detailed groupings in each of the four types of B2B EC, can be developed and proposed.

\section{ACKNOWLEDGEMENT}

This study was supported by 2014 Kyungpook National University (2014 KNU) AS research fund. I am greatly appreciative of the financial support of 2014 KNU AS research fund. 


\section{REFERENCES}

Abbeele, A., Roodhooft, F., \& Warlop, L. (2009). The effect of cost Information on buyer-supplier negotiations in different power setting. Accounting, Organizations and Society, 34, 245-266.

Albrecht, C., Dean, L., \& Hansen, V. (2005). Marketplace and technology standards for B2B e-commerce: progress, challenges, and the state of the art. Information \& Management, 42(6), 865-875

Barua, A., \& Mani, D. (2014). Augmenting conflict resolution with informational response: A holistic view of governance choice in business process outsourcing. Journal of Management Information Systems, 31(3), 72-105.

Barua, A., Konana, P., Whinston, B., \& Yin, F. (2001). Driving e-business excellence. Sloan Management Review, 38, 36-44.

Boonstra, A., \& Vries, J. (2008). Managing stakeholders around inter-organizational systems: a diagnostic approach. Journal of Strategic Information Systems, 17(3), 190-201.

Caker, M. (2008). Intertwined coordination mechanisms in inter-organizational relationships with dominated suppliers. Management Accounting Research, 19(3), 31-251.

Chang, H., \& Wong, H. (2010). Adoption of e-procurement and participation of e-marketplace on firm performance: trust as a moderator. Information \& Management, 47(5-6), 262-270.

Cheng, J. (2011). Inter-organizational relationships and information sharing in supply chains. International Journal of Information Management, 31(4), 374-384.

Cheng, J., \& Fu, Y. (2013). Inter-organizational relationships and knowledge sharing through the relationship and institutional orientations in supply chains. International Journal of Information Management, 33(3), 473-484.

Das, T. K., \& Teng, B. (1996). Risk types and inter-firm alliances structures. Journal of Management Studies, 33(6), 827-43.

Dedrick, J., Xu, X., \& Zhu, X. (2008). How does information technology shape supply-chain structure?: evidence on the number of suppliers. Journal of Management Information Systems, 25(2), 41-72.

Dekker, C. (2004). Control of inter-organizational relationships: evidence on appropriation concerns and coordination requirements. Accounting, Organizations and Society, 29(1), 27-49.

Donada, C., \& Nogatchewsky, C. (2006). Vassal or lord buyers: how to exert management control in asymmetric inter-firm transactional relationships? Management Accounting Research, 17(3), 259-287.

Grover, V., \& Saeed, A. (2007). The impact of product, market, and relationship characteristics on inter-organizational system integration in manufacturer-supplier dyads. Journal of Management Information Systems, 23(4), 185-216. 
Hackney, R., Burn, J., \& Salazar, A. (2004). Strategies for value creation in electronic markets: towards a framework for managing evolutionary change. Journal of Strategic Information Systems, 13(2), 91-103.

Hartono, E., Li, X., Na, K., \& Simpson, T. (2010). The role of the quality of shared information in inter-organizational systems use. International Journal of Information Management, 30(5), 399-407.

Huo, B., Zhang, C., \& Zhao, X. (2015). The effect of IT and relationship commitment on supply chain coordination: A contingency and configuration approach. Information \& Management, 52(6), 728-740.

Iyer, N. S., Germain, R., \& Claycomb, C. (2009). B2B e-commerce supply chain integration and performance: a contingency fit perspective on the role of environment. Information \& Management, 46(6), 313-322.

Kurnia, S., Karnali, R., \& Rahim, M. (2015). A qualitative study of business-to-business electronic commerce adoption within the Indonesian grocery industry: A multi-theory perspective. Information \& Management, 52(4), 518-536.

Overby, E., \& Mitra, S. (2014). Physical and electronic wholesale markets: An empirical analysis of product sorting and market function. Journal of Management Information Systems, 31(2), 11-46.

Patnayakuni, R., Rai, A., \& Seth, N. (2006). Relational antecedents of information flow integration for supply chain coordination. Journal of Management Information Systems, 23(1), 13-49.

Rai, A., Brown, P., \& Tang, X. (2009). Organizational assimilation of electronic procurement innovation. Journal of Management Information Systems, 26(1), 257-296.

Ring, S., \& Van de Ven, H. (1992). Structuring cooperative relationships between organizations. Strategic Management Journal, 13(7), 483-498.

Seddon, P.B. (2014). Implications for strategic IS research of the resource-based theory of the firm: A reflection. Journal of Strategic Information systems, 23(4), 257-269.

Son, J., \& Benbasat, I. (2007). Organizational buyers' adoption and use of B2B electronic marketplaces: efficiency- and legitimacy-oriented perspective. Journal of Management Information Systems, 24(2), 55-99.

Son, J., Narasimhan, S., \& Riggins, J. (2005). Effects of relational factors and channel climate on EDI usage in the customer-supplier relationship. Journal of Management Information Systems, 22(1), 321-353.

Tang, E., Shee, Y., \& Tang, T. (2001). A conceptual model for interactive buyer-supplier relationship in electronic commerce. International Journal of Information Management, 21(1), 49-68.

Toit, A. S. A. (2015). Using environmental scanning to collect strategic information: A South African survey. International Journal of Information Management, 36(1), 16-24. 
Wang, T. G., Tai, C. F., \& Grover, V. (2013). Examining the relational benefits of improved inter-firm information processing capability in buyer-supplier dyads. MIS Quarterly, 37(1), 149-173.

Wong, W.Y., Lai, K., \& Cheng, T. (2012). Value of information integration to supply chain management: roles of internal and external contingencies. Journal of Management Information Systems, 28(3), 161-199.

Youn, S.H., Yang, M., Kim, J. H., \& Hong, P. (2014). Supply-chain information capabilities and performance outcomes: An empirical study of Korean steel suppliers. International Journal of Information Manaqement, 34(3), 369-380.

Zhao, K., \& Xia, M. (2014). Forming interoperability through inter-organizational systems standards. Journal of Management Information Systems, 30(4), 269-298.

Zhu, Z., Zhao, J., Tang, X., \& Zhang, Y. (2015). Leveraging e-business process for business value: A layered structure perspective. Information \& Management, 52(6), 679-691. 